Bull. Mater. Sci., Vol. 15, No. 1, February 1992, pp. 77-89. (C) Printed in India.

\title{
Standardization for advanced materials: experience and strategies for the future
}

\author{
KAMAL HOSSAIN \\ National Physical Laboratory, Teddington, Middlesex, TW11 0LW, UK
}

\begin{abstract}
Materials technology has been identified by most industrialized nations as a key enabling technology which will provide major economic and competitive advantages to industry. Numerous market forecasts show a strong growth potential in advanced materials applications in diverse industrial sectors. This paper discusses the need for standards and standardized methods for material specification and how this can stimulate the market by providing increased confidence in the design and performance of products.

Only a limited number of standards exist for advanced materials, but recently there has been an upsurge of interest worldwide and some countries are very active in developing standards. This is illustrated for some key materials sectors such as advanced ceramics and polymer-matrix composites. Standardization of test and evaluation methods for advanced materials is seen by many countries as a priority area. Methods used for conventional materials can be modified but in some cases new methods have to be developed, both of which approaches require underpinning research.

Trade in materials is international in nature and therefore it is very important to harmonize national standards and develop truly international standards which will help remove technical barriers to trade. This requires effort at a national level in order to collaborate in the international fora and negotiate from a position of strength. Both producers and users of materials need to become involved in standards-related activities. In underpinning prestandards research VAMAS, the Versailles Project on Advanced Materiais, plays an important role and is developing an internationally recognized technical infrastructure from which standards can be developed. This paper discusses the need and scope for international collaboration in standards-related activities.
\end{abstract}

Keywords. Standardization; advanced materials; advanced ceramics; International Standardization Organizations.

\section{Introduction}

The economic importance of advanced materials is now recognized worldwide and high priority is being attached to the development of materials technology by USA, Japan, EC and various other industrialized nations. Competitiveness of industry and its long-term survival depend upon a continuous commitment to product improvement and innovation. Materials account for nearly $60 \%$ of the manufacturing cost of industrial products and successful application of new materials is becoming vital for many industrial sectors.

As materials technology and its application is progressing rapidly, the need for standardization has grown in importance. In this paper an overview of standardization activities in advanced materials is given, addressing some of the key issues and the scope for international cooperation.

This paper was presented at the National Workshop on Standardization for Advanced Materials, Strategic Issues, a collaborative effort of Bureau of Indian Standards (BIS), National Materials Policy Project (TIFAC/DST) and Confederation of Engineering Industry (CEI). 


\section{Advanced materials}

Modern engineering materials fall into three principal categories: (i) metals, (ii) ceramics and (iii) polymers. Metals are well established in engineering application but advances in processing and alloying technology are continuing to improve the performance of metallic materials to their limit and provide new scope. Compared with metals, ceramics have superior wear resistance, chemical stability, high temperature strength and low thermal conductivity properties but suffer from brittleness. The thrust in ceramics development is in processing and control of defects to increase product reliability. Innovation in polymer industry is steadily helping to extend temperature capability and physical, chemical and mechanical performance. All three classes of materials can be either "functional" (e.g. special magnetic/optical properties) or "structural" i.e. load-bearing in nature. Standardization issues are more extensive and complex for structural materials and the present paper will concentrate in this area.

In the development of structural materials, "composites" represent a cornerstone for progress. These are materials which consist of fibrous or particulate reinforcements held together by a common matrix and have properties superior to those of its constituents. They fall into three key categories:

- metal-matrix composites (MMC),

- ceramic-matrix composites (CMC),

- polymer-matrix composites (PMC).

There is no commonly accepted definition of "advanced materials", and any definition will always have ambiguities and exceptions. However, generally speaking, materials which exhibit properties such as high specific stiffness, high temperature strength and high environmental resistance that are significantly better than those of more conventional materials such as steel and aluminium, can be described as advanced materials. An impressive aspect of advanced materials is that they can be tailor-made to have properties, in required spatial directions if necessary, for specific applications. Hence, sometimes they are known as "engineered materials".

Examples of typical advanced materials are:

Metals: superalloys, shape memory alloys, rapidly solidified materials;

Polymers: thermoplastics, polymer blends, elastomers, adhesives, inorganic polymers; Ceramics: alumina, zirconia, silicon nitride, silicon carbide, coatings;

Composites: aramid fibre composites, s-glass composites, carbon-fibre composites, $\mathrm{SiC}$ reinforced $\mathrm{Al}$ or $\mathrm{Ti}$.

Advanced materials may cost 100 times more per unit weight than conventional materials and this means exploitation depends upon the relative importance of cost and performance. Aerospace, automobile and transport industries act as catalysts in the development and wider diffusion of these materials. Market forecasts for advanced materials made in the early 1980 s were optimistic, but most industrialized countries still see a strong growth potential in advanced materials over the next decade. Accordingly, high priority is being given to materials $\mathbf{R} \& \mathrm{D}$ in many countries.

\section{Need for standards}

Setting of standards in a rapidly moving technology poses serious problems and materials technology is no exception to this. Although enormous advances are being 
made in the understanding and quantification of materials characteristics and behaviour, the technical basis from which widely acceptable standards can be developed are still inadequate in many areas. For example, except for isolated standards such as ISO 6474 on "implants for surgery: ceramic materials based on alumina", standards for advanced structural ceramics are not currently available. However, standards are needed for the generation of design data and for reliable specifications for advanced materials. Areas that would benefit from the formulation and application of standards include quality control, product specification and most importantly, materials testing.

Such standards will provide assurance of end-use performance and confidence which designers and production engineers require for changing from traditional to newer materials in products. They must be able to establish whether a new product made from different materials or by a different process will perform in service better than an existing product. By instilling such confidence, standards and codes of practice should stimulate the acceptance and use of advanced materials and thereby create new markets. Standards also enable consumer protection, safety and environmental requirements to be met.

The need for standardised test methods has long been identified as an important priority. For metallic materials, testing methods are well established although there is room for improving accuracy and quantification. However, for brittle materials (technical ceramics), advanced polymeric materials and composites there is considerable difficulty at present in achieving consensus on test methods. Indeed, there are often large disagreements on results and also on what is actually being measured by a non-standard method.

Trade in materials is truly international in nature and therefore it is important that standards are developed on an international basis wherever possible and harmonised when national standards exist.

\section{The international scene in materials standards}

\subsection{Europe}

The most dramatic change in the standardization field is taking place in Europe. In preparation for the Single European Market from the end of 1992, the Committee for European Standards, CEN (Comite Europeen de Normalization) and associated bodies such as CENELEC have seen a strong upsurge in the work programme. Key features of European standardization are as follows:

- Membership of European Standards Bodies is open to EEC and EFTA countries - 18 in all. The text for a standard is adopted by a complicated form of weighted voting.

- Once a European Standard (EN) is agreed any conflicting national standard must be withdrawn and the EN must be adopted unchanged by a member country if a national standard is required subsequently.

New standards committees are being set up continuously and in the advanced materials field we can expect to see a significant level of activity. However, because of the timescale and the sheer volume of work, the EC will adopt, with appropriate modifications, national or international (ISO) standards to avoid duplication of effort and to make the best use of scarce resources available for standardization work. 


\subsection{Japan}

In parallel with its heavy $R$ \& $D$ investment in materials, Japan has identified standards as a key issue. In 1987 a Special Committee for the Standardization of Advanced Materials was set up by the Japanese Industrial Standards Committee (JISC) in the Agency of Industrial Science and Technology (AIST) under MITI. Four subcommittees were established to survey standardization needs and feasibility of standards development covering the fields of metals, high polymers, ceramics and user needs.

The Committee recommended that standardization of terms and symbols, and testing and evaluation methods should be given priority (JISC 1988). A summary of their findings is given in table 1.

Following the recommendation of the Committee, a five-year plan for the promotion of industrial standardization was launched in April 1991. The highlight of the plan is Japan's new policy for harmonization of JIS standards with ISO and IEC standards, whereby all JIS standards will be-subject to review with regard to their compatibility with relevant ISO and IEC standards.

\section{$4.3 U S A$}

ASTM, the American Society for the Testing of Materials, is the most active body in USA in the materials standards field. It has an open membership which allows individuals from any country to participate and relies primarily on collaborative, voluntary effort by industry and consumers in the development of standards through consensus based on broad experience. The American National Standards Institute (ANSI), is the official standards organization and acts for the USA in ISO work.

Table 1. Standardization need and priorities in Japan.

\begin{tabular}{|c|c|c|c|}
\hline $\begin{array}{l}\text { Type of advanced } \\
\text { material }\end{array}$ & $\begin{array}{l}\text { Number of } \\
\text { standards } \\
\text { needed }\end{array}$ & $\begin{array}{l}\text { Number of standards } \\
\text { to be developed in } \\
\text { the next } 10 \text { years }\end{array}$ & Priority areas \\
\hline $\begin{array}{l}\text { (i) Metal-based } \\
\text { materials }\end{array}$ & 467 & 143 & $\begin{array}{l}\text { New functional materials, (e.g. super- } \\
\text { conducting materials), materials } \\
\text { produced by advanced processing } \\
\text { (e.g. powder metals) and high functional } \\
\text { materials (e.g. heat-resistant, low } \\
\text { thermal expansion) }\end{array}$ \\
\hline $\begin{array}{l}\text { (ii) High polymer- } \\
\text { based materials }\end{array}$ & 106 & 94 & $\begin{array}{l}\text { Evaluation of mechanical properties, } \\
\text { thermal properties, chemical properties } \\
\text { and durability }\end{array}$ \\
\hline $\begin{array}{l}\text { (iii) Ceramics- } \\
\text { based materials }\end{array}$ & $\begin{array}{l}227 \text { (fine ceramics) } \\
227 \text { (glass) }\end{array}$ & $\begin{array}{l}219 \text { (fine ceramics) } \\
203 \text { (glass) }\end{array}$ & $\begin{array}{l}\text { Ceramics: Mechanical and thermal } \\
\text { properties. Raw powder, manufactur- } \\
\text { ing processes and chemical properties. } \\
\text { New Glasses: Optical, magnetic. }\end{array}$ \\
\hline $\begin{array}{l}\text { (iv) Common- } \\
\text { tenting for different } \\
\text { classes of materials }\end{array}$ & - & 26 & 一 \\
\hline
\end{tabular}


Standards, particularly the need for standard test and evaluation methods, are seen as a key issue for advanced materials in the USA (US Congress 1988).

There are over 120 technical committees in ASTM covering seven main categories: (a) ferrous metals, (b) non-ferrous metals, (c) cementitous, ceramic, concrete and masonry materials, (d) miscellaneous materials, (e) miscellaneous subjects, (f) materials for specific applications and (g) corrosion, deterioration and degradation of materials.

\subsection{International Organization for Standards (ISO)}

ISO covers standardization in all fields except electrical and electronic engineering which is covered by the International Electrotechnical Commission (IEC). ISO is a federation of national standards bodies with no individual membership. As in CEN, the technical work is done through Technical Committees (TC) which may appoint subcommittees (SC) and working groups (WG). The WG output is a Draft International Standard (DIS) on which all number bodies can vote; there are 73 full members and 15 correspondent members.

ISO has a number of committees dealing with modern engineering materiais, but there are not yet many international standards in advanced materials.

\section{Current position in standardization programmes}

Programmes in various categories of materials are too many to discuss in this paper; however, some of the key areas are chosen to highlight different aspects and issues related to standardization.

\subsection{Advanced ceramics}

Over the past decade various market projections have shown a strong growth potential in advanced ceramics. Worldwide this has stimulated heavy investments in R \& D and standards are seen widely as an appropriate means to support the development of these materials and to promote their acceptance. A number of countries have initiated standardization activities. The main thrust of this standards work is for structural applications, particularly in the areas of materials analysis, characterization and mechanical testing. The drive for standardization stems from:

(i) poor market penetration due to lack of confidence in performance;

(ii) variations in test methods for material and component specifications;

(iii) difficulty in comparing data from different sources; and

(iv) lack of design data obtained using validated methods.

Last year CEN set up a new Committee, TC184, with five working groups (table 2) to develop standards for advanced ceramics with the remit that 42 standards be prepared by the end of 1992. Such a mandate shows clearly the importance Europe is placing on standardization in this area. Also evident is the emphasis being placed on test methods standardization. Current knowledge suggests that there are a number of areas where existing test procedures can be modified or corrected to take account of the behaviour and characteristics of advanced ceramics. However, in several key 
Table 2. Work programme of CEN TC184.

\begin{tabular}{lll}
\hline Working group & Area of work & $\begin{array}{l}\text { Number of items } \\
\text { in hand }\end{array}$ \\
\hline WG1 & $\begin{array}{l}\text { Terminology and } \\
\text { classification } \\
\text { Wow }\end{array}$ & 1 \\
WG & $\begin{array}{l}\text { characterization } \\
\text { Test methods for } \\
\text { monolithic ceramics }\end{array}$ & 15 \\
WG4 & $\begin{array}{l}\text { Test methods for } \\
\text { ceramic matrix } \\
\text { composites }\end{array}$ & 13 \\
WG5 & $\begin{array}{l}\text { Test methods for } \\
\text { ceramic coatings }\end{array}$ \\
\hline
\end{tabular}

areas there is a clear requirement for an improved technical base from which standards can be developed. Such areas are:

- biaxial strength

- fracture toughness

- static and cyclic fatigue

- improved non-destructive evaluation
- surface quality

- tensile strength tests

- slow crack tests

- impact/erosion tests

- proof test procedures

There is no ISO activity currently in advanced ceramics except for biomedical implants, but both Japan and ASTM (Committee C-28) are very active. In fact, most advances in developing standardized test procedures for ceramic materials and components are in Japan and the UK. France has the lead in considering properties of powders and ceramic-matrix composites.

\subsection{Polymers and polymer-matrix composites (PMCs)}

Polymers have been in wide use for many years and in fact the volume of plastics on the worldwide market now exceeds that of metals. Current developments centre on engineering polymers with improved mechanical and thermal properties. Polymermatrix composites fall into two main categories:

(a) glass reinforced plastics typically based on thermosetting resins with low stiffness glass-fibres. These have been in use for $30-40$ years in transport, marine and leisure-goods industries;

(b) advanced composites based on epoxies reinforced with fibres of high-stiffness glass (s-glass), graphite, aramid or other organic fibres are used in high-value added products for aerospace, sports equipment and engineering and automotive sectors.

Although advanced composites represent only a small percentage (about $5 \%$ ) of the overall market, these are expected to grow at a relatively high rate.

Worldwide there is considerable activity in plastics and composites standardization (Traceski 1990). ISO has a well established Technical Committee, TC61, now operating 
Table 3. ISO Technical Committee 61 on plastics.

\begin{tabular}{lll}
\hline $\begin{array}{l}\text { Sub-committee } \\
\text { No. }\end{array}$ & Title & $\begin{array}{l}\text { No. of existing } \\
\text { working groups }\end{array}$ \\
\hline SC1 & Terminology & 4 \\
SC2 & Mechanical properties & 10 \\
SC4 & Burning behaviour & 4 \\
SC5 & Physical chemical properties & 9 \\
SC6 & Ageing chemical and & 5 \\
& environmental resistance & \\
SC9 & Thermoplastic materials & 11 \\
SC10 & Cellular materials & 7 \\
SC11 & Products & 4 \\
SC12 & Thermosetting materials & 6 \\
SC13 & Composites and reinforce- & 6 \\
& ment fibres & \\
\hline
\end{tabular}

with ten sub-committees and nearly 65 working groups (table 3). Over 275 ISO standards for plastics materials and products have been published.

It is interesting to examine the standardization scene for advanced PMCs in more detail.

(a) International: Almost all of the existing ISO standards deal with glass fibre reinforced plastics. Only recently SC13 has produced several draft documents for carbon fibres and their composites. As standards come up for regular review ISO plans to extend their applicability to advanced composites and with this in mind SC13 has now set up a strategy committee to review data and test methods for advanced PMCs. In the advanced composites field, again, the need for standardized test methods for determining the engineering properties of composites has been recognized widely. However, the issues involved are complex and, although there is no easy solution, some promising developments are taking place.

(b) Europe: CEN has a committee TC249 to address plastics standardization which has a subcommittee SC2 dealing with composites standards. Currently, there are no CEN standards for advanced composites. There are also some important initiatives led by the aerospace industry, particularly AECMA (The European Aircraft Manufacturers' Association) and ACOTEG (consortium of three large players in Europe-BAe, MBB and Aerospatiale). AECMA as an industry association can directly interact with the working group in CEN to produce Aerospace series standards.

UK and Germany are also very active in Europe. In the UK a very useful series of test methods were developed collaboratively by the Ministry of Defence and the Society of British Aerospace companies under CRAG - the Composites Research Advisory Group (Curtis 1988). These methods cover engineering properties for design, quality control, and physical and environmental properties. NPL, in the UK, is now working with BSI committee PRM41 and the British Plastics Federation to validate these methods with the aim of providing an input to CEN and ISO. 
There are many initiatives globally to develop standards for advanced structural composites. For the key area of standardized test methods, various test procedures with significant similarities exist and it appears that the primary task is to validate and harmonize these test methods so that a consistent and reliable set of international standards can be developed.

(c) USA: ASTM's committee D30 is active and so is SACMA, the Suppliers of Advanced Composites Materials Association. In test methods, SACMA is building on existing ASTM standards to extend their scope with the aim of subsequently offering the results to ASTM for standardization. The US army is leading efforts to harmonize the Department of Defence requirements using ASTM standards when possible.

(d) Japan: JIS are developing a significant number of standards.

\subsection{Metal-matrix composites}

Relative to advanced ceramics and PMCs, standardization of modern metal-based materials is well developed. However, for new developments such as metal-matrix composites the situation is quite different. In some of the most advanced industrialized nations, significant investments are being made to develop MMCs because the demand for these materials is expected to grow in airframes, reciprocating parts in automobiles, leisure goods and various other industrial applications. Designers need good reliable design data to realize the market potential but at present there is a serious lack of proven or standardized test methods needed for generating the data.

There is only one standard, ASTM D3552, directly applicable to the mechanical testing of MMCs for the tensile testing of fibre-reinforced metals. In the UK, NPL carried out a survey which showed that, in most cases, standards used for metals are being adopted for testing MMCs. These are likely to be satisfactory to a degree for particulate reinforced MMCs which are reasonably isotropic, but for fibre-reinforced MMCs other techniques are being assessed including methods developed for PMCs.

At NPL, recent round-robin testing and other measurement work on MMCs have demonstrated clearly the need for pre-standardization research to identify the limitations associated with metals standards before these can be confidently applied for testing MMCs (Hossain et al 1991). Modifications of metals standards are likely to be needed at least for measuring modulus, fracture toughness testing, dealing with macroscopic residual stresses and the effects of test-piece machining on fatigue tests. Standards development for MMCs is thus at an early stage and international efforts, if coordinated, could bring considerable benefits.

\section{The role of VAMAS in standardization for advanced materials}

VAMAS, the Versailles Project on Advanced Materials and Standards, was set up to support trade in high technology products through international collaboration in the development of technical base from which standards, codes of practice and specifications for advanced materials can be drafted. VAMAS arose out of the Economic Summit meeting in 1982 in Versailles and operates under a Memorandum of Understanding signed in 1987 by the Summit nations, Canada, France, Germany, 
Table 4. VAMAS technical working areas.

\begin{tabular}{|c|c|c|c|}
\hline Area No & Title & Materials under study & Chair \\
\hline TWA1 & Wear test methods & Alumina, silicon nitride, AISI 52100 steel & USA, Germany \\
\hline TWA2 & Surface chemical analysis & $\begin{array}{l}\text { Wide ranging reference materials, metaliic } \\
\text { and non-metallic }\end{array}$ & UK \\
\hline TWA3 & Ceramics & Alumina, zirconia-alumina & USA \\
\hline TWA4 & Polymer blends & $\begin{array}{l}\text { Polycarbonate/polyethylene blend, } \\
\text { Orgalloy R- } 6000 \text { commercial blend }\end{array}$ & Canada \\
\hline TWAS & Polymer composites & Glass and carbon fibre reinforced resins & France \\
\hline TWA6 & $\begin{array}{l}\text { Superconducting and } \\
\text { cryogenic structural } \\
\text { materials }\end{array}$ & $\begin{array}{l}\text { Niobium-tin and niobium-titanium } \\
\text { filaments, cryogenic steels }\end{array}$ & Japan \\
\hline TWA7 & Bioengineering materials & Hydroxyapatite, alumina, zirconia & Japan \\
\hline TWA8 & $\begin{array}{l}\text { Hot-salt corrosion } \\
\text { resistance }\end{array}$ & $\begin{array}{l}\text { Rene } 80 \text { and IN } 738 \text {, nickel-base super- } \\
\text { alloys, protective coatings }\end{array}$ & UK \\
\hline $\begin{array}{l}\text { TWA9 } \\
\text { (completed) }\end{array}$ & Weld characteristics & 304 and 316 stainless steels & UK \\
\hline TWA10 & Material databanks & $\begin{array}{l}\text { Creep and fatigue data from low and } \\
\text { high alloy steels }\end{array}$ & EC, USA \\
\hline TWA11 & Creep crack growth & $\begin{array}{l}\text { Chromium/molybdenum/vanadium } \\
\text { ferritic steels }\end{array}$ & UK \\
\hline TWA12 & $\begin{array}{l}\text { Efficient test procedures } \\
\text { for polymer properties }\end{array}$ & Wide range of polymers & UK \\
\hline TWA13 & Low-cycle fatigue & $\begin{array}{l}\text { IN } 718 \text { and Nimonic } 101 \text { nickel-base } \\
\text { alloys, } 316 \mathrm{~L} \text { and } 9 \mathrm{Cr} / 1 \mathrm{Mo} \text { steel }\end{array}$ & $\mathrm{EC}$ \\
\hline TWA14 & $\begin{array}{l}\text { Technical basis for a } \\
\text { unified classification } \\
\text { system }\end{array}$ & Engineering ceramics & USA \\
\hline
\end{tabular}

Italy, Japan, UK and USA, often referred to as the G7 countries now, and the CEC. VAMAS is led alternatively by UK and USA every three years; currently the National Physical Laboratory in the UK holds the Secretariat.

Pre-standards research under VAMAS is organized through a number of Technical Working Areas (TWAs) each led by a chairman (or two co-chairmen). Nearly sixty projects have been initiated so far. Research is undertaken on a work-sharing basis with no transfer of funds between signatory nations. A lisi of TWAs, fourteen altogether, are shown in table 4, while details of the work programme and results can be found in VAMAS Bulletins, currently published every six months (see VAMAS $B u l l$ ). Table 4 shows that the materials covered by the TWAs are wide ranging and embrace organic, metallic and ceramic classes as well as thin films, coatings and composites. Engineering properties being investigated include:

Thermal mechanical (hardness, tensile, creep, fatigue and fracture toughness)

Electrical Environmental (corrosion and wear) 
In addition, materials classification and databank standardization issues are being addressed.

Over 350 research groups have taken part in VAMAS from industrial, academic and government laboratories. The pre-competitive nature of the work has meant that industry has been able to provide valuable materials and other forms of support which has benefitted the whole programme. Similarly, cooperation between government laboratories in different countries has been significant and the combined efforts have assisted the resolution of complex issues in a sensible and cost-effective way.

Participation in VAMAS has not been limited to summit nations. With the unanimous agreement of member nations, researchers from eight non-summit countries-Austria, Belgium, Denmark, Finland, Netherlands, Portugal, Sweden and Switzerland - have contributed to one or more projects in nine TWAs.

Based on VAMAS results, so far two standards have been completed and eleven more are being prepared. In addition, measurement guidelines, codes of practice, data transfer formats and reference materials have been developed and are in use. There is also a significant body of publications in scientific journals and the open literature, showing the value of international collaboration in underpinning pre-standards research.

The scope of this paper does not allow us to describe the work of the TWAs in detail, but it might be interesting to discuss some specific topics which should provide an insight into the operation of VAMAS.

\subsection{Examples of VAMAS activities}

Technical Working Area 1 in VAMAS is concerned with wear testing of advanced materials. Wear performance of materials is an important design parameter in many applications and although various methods for measuring wear are available, standardization has always proved difficult to achieve. Under VAMAS nearly 40 laboratories collaborated to investigate the tribological behaviour of advanced ceramic materials (alumina, silicon nitride and AISI 52100 steel) under dry sliding conditions and established internationally agreed test methodologies with improved reproducibility and comparability. As a result two standards have been published (ASTM 1990; Tribology 1991).

Technical Working Area 2 deals with surface chemical analysis techniques such as Auger electron spectroscopy (AES), X-ray photoelectron spectroscopy (XPS) and secondary ion mass spectroscopy (SIMS) which are being widely used by industry and researchers. The objective of the VAMAS work is to provide by coordinated effort the reference procedures, reference data and reference materials necessary to establish standards for surface chemical analysis. Over 30 projects are covered in this area with participation from nearly 100 laboratories. Already the VAMAS work has produced reference materials, a standard data transfer format and recommendations for standardized energy and intensity scale calibration methods for AES. Notably, following a recent Japanese initiative, the work of the TWA has been considered so important that a new ISO TC has been set up which in future will accelerate the transfer of the VAMAS TWA results into international standards.

In the advanced ceramics field VAMAS has established two Technical Working Areas-TWA3 and TWA14. TWA3 is dealing with important pre-standards research 
for critical mechanical properties measurements such as fracture toughness and dynamic fatigue. TWA14 commenced its work in 1989 with an international survey of industrial classification requirements and practices. About 125 organizations responded to a questionnaire which demonstrated the urgent need for a classification system which would serve users and producers alike. The VAMAS group is well advanced in preparing a matrix classification scheme which will provide the basis for an international standard by the end of 1992 .

Thus, internationally, VAMAS has established itself in the leading position in prestandards research in the advanced material field. An independent review of the work and achievements of VAMAS was completed earlier this year and the review team has strongly recommended for continuation of VAMAS at least until 1997.

\section{Strategy for the future}

It is very timely to analyse the key issues pertinent to standardization in the advanced materials field. Sometimes the view is expressed that standardization is not very appropriate for rapidly growing technology because standards can be a barrier to progress and are needed only for establishing market share once a market has developed. For advanced materials this line of argument cannot be sustained easily since standardization is needed to stimulate new applications and market by increasing confidence and reliability in products made from them. Particularly important in this context is the need to develop widely acceptable test and measurement methods.

There is a growing $R$ \& $D$ drive in many countries in advanced materials, and an important challenge that lies ahead is to integrate standardization work with this R \& D. There is evidence that this point is being recognized more widely now, particularly in relation to pre-standards effort.

Standardization of advanced materials is at an early stage. Often such materials are first used by the aerospace industry where cost is less important than performance. A standard developed by the aerospace industry for its own use may not be suitable for the engineering industry in general and more work is often needed to translate the industry-specific standards into broader ones. An example of this is given earlier in the paper in relation to CRAG test methods for polymer composites developed in the UK by the Ministry of Defence and the aerospace industry. Standards-making is a slow process and therefore it is important that wider sectors of industry become involved as early as possible if the opportunities offered by the technology are to be seized.

Very important is the participation of user industries. By its nature materials is an enabling technology and the users are widespread into different sectors. The materials supply industry tends to dominate standardization activities whilst users do not become sufficiently involved. The problem is not easy to solve because user industries have other pressures to cope with and they are content to leave standardization to suppliers. However, effort must be made to attract users into standards-related activities whenever possible. The benefits will be significant.

Trade in materials is international in character. A material developed in one country can be produced in another and subsequently incorporated in industrial products in other countries. Thus, it is important that specifications, codes of practice and standards are developed on an international basis. However, does this mean a country can leave 
the development of materials standards to other countries? This would be a very high risk policy. A presence in the international standards forum ensures that national interests, and here one must remember producers as well as users of materials, are looked after adequately. This can be achieved successfully only if there is a strong domestic base and activity in standards-related work. One can then negotiate from a position of strength and knowledge.

Important changes are taking place in the international standards scene. With the rapid approach of the Single European Market, CEN has a mandate to produce a large number of standards quickly. They have established important committees in the advanced materials field and the trend will continue. USA and Japan are also very active and hence it is important that a coordinated approach is taken in liaison with ISO. Only a limited amount of resources is available in each country for standardization work and the best use of this resource must be made.

Priority setting for standards work is also a key issue. A work programme developed on the basis of identical needs has to be matched to available resources. With increasing pressure on standards bodies, more effort will be needed to establish clearly timeliness and priority on a regular basis.

From earlier discussions it is evident that standardization of evaluation and test methods for advanced materials often presents a serious problem because of a lack of a proper technical base. Pre-standardization research provides the solution, but it is time-consuming and resource-intensive, so there is a strong case for working on a cooperative basis internationally. VAMAS has proven to be an effective model and vehicle for this kind of activity and there is significant scope for building on its success.

Pre-standards research must also be well-directed and address future standardization needs clearly. Therefore, VAMAS has steadily built up good links with standards bodies. Very importantly VAMAS now expects to sign a Memorandum of Understanding with ISO which will enable the two organizations to publish jointly guidelines on test methods, methods of specifications etc. based on VAMAS work. This will be an important step forward because it will provide immediate assistance to industry and users of advanced materials before a standard can be processed through the normal route.

\section{Conclusions}

Globally, there is a growing drive for advanced materials standards. To meet the requirements, efforts are being made at the national and international levels and it is important that these activities are coordinated to develop harmonized and international standards. Important changes are taking place in the international standards scene and effort should be made to develop advanced materials standards in an efficient way to make the best use of limited resources. Pre-standards research has a vital role in accelerating standards making, and the VAMAS model has proved effective for generating internationally agreed technical bases from which standards can be developed. There is significant scope for strengthing this kind of activity with support from industry and governments. 


\section{References}

ASTM 1990 ASTM standard test method for wear testing with a pin-on-disk apparatus G99-90

Curtis P T 1988 CRAG test methods for measurement of the engineering properties of fibre reinforced plastics, UK Royal Aircraft Establishment Report, TR 88012, 3rd edition

Hossain-M K, Lord J D and Sims G D 1991 Testing and standards on advanced composites, Proc. Conf. on Advanced Materials Evaluations, Birmingham

JISC 1988 Standardization of advanced materials-Summary report of the special committee on standardization of advanced materials, JISC, Agency of Science \& Technology, Japan, Sept. 1988

Traceski F T 1990 Specifications and standards for plastics and composites, ASM Publication, August 1990

Tribology 1991 Measuring friction and wear, DIN 50324, Model experiments on sliding friction in solids

US Congress 1988 Office of Technology Assessment, Advanced materials by design, OTA-E-351, Library of Congress Catalogue card No. 87-619860, June 1988

VAMAS Bulletin, Published by VAMAS Secretariat, currently at National Physical Laboratory, Teddington, UK

VAMAS 1991 Technical Report No. 5, International survey on the classification of advanced ceramics, ISSN 1016-2186 